\title{
DIE METODOLOGIESE VERBAND TUSSEN DIE EKONOMIE EN ENKELE ANDER SOSIALE WETENSKAPPE
}

\section{Die probleem}

Nieteenstaande die feit dat die ekonomie op 'n gevorderde vlak in sy ontwikkelingsproses verkeer, is daar nog sekere metodologiese aspekte waaroor veel gediskusseer word en waaroor daar nog geensins eenstemmigheid bereik is nie.

Hierdie aspekte val in drie kategorieë uiteen, naamlik, eerstens die sogenaamde algemene ,vergissings", tweedens die verband van die ekonomie met ander sosiale wetenskappe en derdens die suiwer wetenskaplike of positiewe versus die Christelik-normatiewe siening van die aard en omvang van die ekonomie. Die tweede en derde groepe oorvleuel egter tot 'n mate terwyl die implikasies van die eerste kategorie deurwerk na die tweede en derde kategorieë.

Wat die sogenaamde algemene „vergissings" in die ekonomie betref, sentreer die besprekings rondom probleme soos die post hoc ergo propter hoc-vergissing, dit wil sê, die veronderstelling dat as 'n sekere veranderlike op 'n ander veranderlike volg dan word laasgenoemde deur eersgenoemde bepaal, of te wel dan die spesifieke kousale verband tussen veranderlikes. 'n Verdere ,vergissing" wat baie aandag geniet is dié van misplaaste realisme. Hier sentreer die diskussies rondom die realiteit van aannames wat in die opbou van ekonomiese teorieë gebruik word en in hoeverre onrealistiese aannames die voorspellingskrag van sodanige teorie beïnvloed.' Nog 'n „vergissing” waaroor veel geskryf word is die sogenaamde Ceteris Paribus-aanname in die ekonomie of waar alle ander veranderlikes as konstant of gegewe aanvaar word. Die analise word dus slegs in terme van een of ' $n$ paar veranderlike faktore gedoen.

'n Ander metodologiese kontroversie handel oor die probleem of die ekonomie suiwer wetenskaplik benader moet word en of dit 'n normatiewe wetenskap is. Hier kan eintlik nog 'n derde standpunt bygevoeg word, naamlik 'n tipe sentritisme waar nie 'n definitiewe standpunt ten opsigte van die positivisme of normatiwiteit van die ekonomie ingeneem word nie. Die basisprobleem hier is eerstens of etiese norme en waar- 
deringe vir die ekonomie data is en of dit elemente van die ekonomiese wetenskap self is en tweedens, as die uiteindelike, of die ekonomie as wetenskap religieus gefundeer is. Die strydpunt wat hierdie saak betref is nie meer die noodsaaklikheid om die ekonomie religieus te fundeer nie of die wenslikheid van etiese norme in die ekonomie nie, maar die moontlikheid om hierdie aspekte in die operasionele raamwerk van die ekonomie te inkorporeer.

Daar word in hierdie artikel enkele aspekte van hierdie drie metodologiese probleemgebiede aangeraak. Dit is onmoontlik om binne die bestek van ' $n$ artikel op enige mate van volledigheid aanspraak te maak. Met die oog op die omvang van die probleem is ' $n$ seleksie van enkele belangrike literatuurverwysings gemaak om sommige van die sentrale aspekte na vore te bring en in 'n kritiese lig te stel.

\section{Filosofiese verwysingsraamwerk}

Voordat enige kritiese analise van sommige van die stand. punte betreffende hierdie metodologiese sake onderneem kan word, moet daar 'n filosofiese verwysingsraamwerk vooropgestel word, waarbinne sodanige kritiek opgebou kan word.

Dit is nie vir die ekonoom om verskillende filosofieë te kritiseer nie, hoewel hy 'n eie filosofie daarop kan nahou. Oor die algemeen aanvaar die ekonoom egter 'n sekere filosofie wat volgens sy leke-mening inpas by die verklaring van die werklikheid en sy persoonlike lewens- en wêreldbeskouing. Die Wysbegeerte van die Wetsidee soos deur Dooyeweerd, Stoker en andere ontwikkel word hier as konseptuele raamwerk aanvaar. Elemente wat implisiet betrokke is, is die verskillende kosmiese dimensies van modaliteite, indiwiduele en sosiale strukture, gebeurtenisse en waardes, tesame met die begrippe dimensionele antisipasies en retrosipasies. Wat die verskillende modaliteite betref, gaan dit nie hier oor die vraag of daar vyftien (Dooyeweerd), twaalf (Stoker), twee (Kant) of enige ander aantal modaliteite is nie maar oor die begrippe sinskern van 'n modaliteit, modale antisipasie en retrosipasie waarby ingesluit die vaste rangskikking van die modaliteite in ' $n$ orde van toenemende retrosiperende kompleksiteit. Verder word die verskillende beginsels naamlik outoriteitsbeginsel, self-evidente beginsel en postulate, veral die postulate van soewereiniteit en universaliteit in eie kring, implisiet gehanteer en veronderstel. 


\section{Die ekonomie in sy metodologiese verband met enkele ander sosiale wetenskappe}

Een van die vroegste pogings om die ekonomie met ander sosiale wetenskappe te integreer het gekom in die vorm van institusionalisme in die ekonomie." John $R$. Commons, een van die skeppers van hierdie benadering, het in die institusionele ekonomie die moontlikheid gesien om kollektiewe sosiale aksie in al sy verskeidenheid ' $n$ regmatige plek in die ekonomiese teorie te gee. Met hierdie uitgangspunt as basis onderskei hy drie basiese beginsels van konflik, afhanklikheid en orde wat saamgesnoer word in ' $n$ uiteindelike aktiwiteitseenheid, genoem die Transaksie, waarin die wet, ekonomie en die etiek gekorreleer word. Verder onderskei hy drie tipes transaksies wat tesame weer 'n lopende bedryf (Going Concern) vorm. ' In hierdie „Going Concern" wat die groot eenheid van ekono. miese aktiwiteit vorm, is daar dus die verskillende sosiaalwetenskaplike kerne deur middel van die verskillende beginsels en transaksies saamgesnoer in 'n eenheid.

Hierdie vroeëre pogings tot sintese in die sosiale wetenskappe in die vorm van institusionalisme, hoewel indrukwekkend in inherente struktuur van analise, moet egter as 'n poging beskou word om swak ekonomie, swak sosiologie en swak antropologie deur 'n medium van onbewuste emosionele vooroordeel te sintetiseer. 'n Sintese tussen sosiale wetenskappe kan tot 'n noemenswaardige resultaat lei alleen as die verskillende betrokke wetenskappe so 'n peil van ontwikkeling bereik het dat algemene beginsels in 'n sinvolle nuwe teoretiese struktuur saamgesnoer kan word. Dit was nie die geval met hierdie wetenskappe in die tyd van die vroeë institusionalisme nie - vandaar dat hierdie pogings vandag slegs geskiedenis is.

Met die kwyning van hierdie vroeë institusionalisme in die ekonomie ontstaan ' $n$ nuwe tipe institusionalisme, of neo-institusionalisme, in die sosiologie waarby die ekonomie regstreeks betrokke is. Die sisteem het begin deurdat sekere sosioloë, veral Talcott Parsons, ernstige kritiek teen die isolerende abstraksie van die ekonomie begin uitspreek het. Hierdie pogings van Parsons het uiteindelik gekulmineer in 'n geskrif wat veronderstel is om 'n groot bydrae te lewer tot die sintese van ekonomiese en sosiologiese teorie.'

Ten einde die nodige perspektief te verkry betreffende 
die verhouding ekonomie-sosiologie soos dit in die kontroversies na vore kom, moet die verskeie pogings om die ekonomiese sinskern of probleemgebied presies te omlyn, baie kortliks geskets word. L. M. Fraser ${ }^{3}$ klassifiseer die definisies van die ekonomiese sinskern in twee groepe, naamlik die Tipe A-definisies wat die ekonomie aan welvaart en rykdom koppel en die Tipe B-definisies wat skaarste as sentrale ekonomiese faktor aanvaar. Hierby kan nog 'n Tipe C-groep gevoeg word, waarvan Ludwig von Mises se praxeologie, wat min of meer met die nuwe institusionalisme in die sosiologie ooreenstem, die hoofverteenwoordiger is.

Om die ekonomie in terme van welvaart of rykdom te definieer is, soos Fraser tereg opmerk, om die ekonomiese sfeer tot ' $n$ departement van die menslike handeling te beperk. Die groot bydrae van Lionel Robbins,' eksponent van die skaarste-konsep, lê daarin dat hy die ekonomiese aktiwiteit as 'n aspek en nie 'n departement van die menslike handeling beskou. Afgesien van die inhoud van Robbins se formulerings, wat uiteraard suiwer wetenskaplik en positief gestel is, het hy gepoog om 'n soewereine probleem en veld vir die ekonomie af te baken.

Robbins se siening van wat die ekonomie presies behels en die kritiek wat daarop gevolg het, illustreer die metodologiese dilemma waarin die sosiale wetenskappe in die opsig verkeer.

Voordat daar egter van 'n ekonomiese aspek gepraat kan word, sê Robbins, moet aan vier voorwaardes voldoen word Daar moet eerstens verskillende behoeftes of doelstellings wees, tweedens moet die tyd en middele om aan die behoeftes te voldoen beperk wees, derdens moet die tyd en middele geskik wees vir alternatiewe aanwending en vierdens moet die behoeftes verskil in belangrikheid. ${ }^{\text {? }}$

Alleen wanneer aan hierdie vier voorwaardes voldoen is, kan gedrag die vorm van 'n keuse aanneem. Keuse, soos deur die vier voorwaardes gekwalifiseer tesame met die twee kompliserende faktore van onvolkome subsitusie van middele ${ }^{s}$ en onsekerheid," blyk dus die basis van feitlik alle ekonomiese teorie te vorm. Dienooreenkomstig definieer Robbins die ekonomie dan as "the science which studies human behavior as a relationship between ends and scarce means which have alternative uses". ${ }^{10}$

Robbins is dus nie gemoeid met menslike gedrag as sodanig nie, maar met keuseaksies soos deur sy vier voorwaardes 
gekwalifiseer. Hierdie spesifieke eienskap van Robbins se idees word nie duidelik deur Fraser ingesien wanneer hy Ludwig von Mises se „Handeln” met Robbins se „economizing” gelykstel nie." Von Mises se aksie-teorie sien die totale menslike handeling as die resultaat van 'n interafhanklikheid van 'n kompleks groep faktore. Hoewel Von Mises die ekonomie as die beste ontwikkelde deel van die wetenskap van die menslike handeling beskou, het hy nooit soewereiniteit aan die ekonomie toegeken nie. Robbins het net die teenoorgestelde probeer doen, naamlik om aan die ekonomie 'n soewereine veld en probleem toe te ken wat onherleibaar tot die sinskerne van ander sosiale wetenskappe is.

Ekonomie, gaan Robbins voort, is nie gemoeid met die behoeftes en doelstellings as sodanig nie. Dit is slegs met die behoeftes gemoeid in soverre dit die aanwending van die middele bepaal. Behoeftes word met mekaar vergelyk en in 'n skaal van relatiewe waardering of belangrikheid geplaas. Middele word gewaardeer om hulle sodoende tot die dringendste gebruik aan te wend. Die kern van Robbins se konsep is dus die handeling om skaars middele te ekonomiseer met betrekking tot ' $n$ verskeidenheid behoeftes wat in 'n spesifieke waardeskaal gerangskik is. Veelheid van behoeftes word 'n voorvereiste vir die ekonomie. Die toedeling van skaars middele na een behoefte is 'n tegniese en nie 'n ekonomiese probleem nie."

Die positiewe ekonomiese teorie en praktyk aanvaar dus die behoeftes en doelstellings as data en nie as element nie. Soos reeds gestel, vorm hierdie aanname die spil waarom die positiewe-normatiewe en die waarde-oordeel kontroversies in die ekonomie draai. ${ }^{13}$

Robbins se eerste kritiek kom van R. W. Souter." In 'n hoogs subjektiewe analise beskou Souter Robbins se benadering as „formalistic, static economic theory" en probeer om dit deur sy eie organiese en dinamiese teorie te vervang wat, indien gereduseer tot sy basis, eintlik op Marshall se prysteorie neerkom. Hierdie kritiek is gemik op die aanvaarding van doelstelling wat doelgerigte aksie elimineer.

Talcott Parsons se kritiek is in die breë dieselfde as dié van Souter. ${ }^{18}$ Hy bou voort op Souter se proposisie dat die sosiale wetenskappe 'n organies verenigde ,society" eerder as 'n atomistiese "nebeneinander" vorm. Gesien uit die sosiologiese oogpunt wil Parsons die aandag van Robbins en Souter op die verhouding tussen instellings en ekonomiese aktiwiteite vestig. 
„Some institutions rest essentially on the ultimate value-attitude of a community, in so far as institutional control plays a part in concrete 'economic' life, in 'business', a sociological element must be considered to be there, beyond the range of economic theory'.

Verder: „And furthermore similar reasoning will soon demonstrate that concrete 'business' is by no means free from what I would term political, technological and even positivistic factors of external environment and man's inherited nature".". (kursivering voorsien).

Beide Souter en Parsons se analises het 'n fundament basis, maar die doelwit van hulle kritiek, in die geval Robbins se "statiese, formele en meganiese ekonomie" is verkeerd. Selfs Robbins sou toegee dat ,a cursory glance at concrete reality will show that the complexities of interrelation of the means-end chains are so great, there is so much interweaving with other chains and turning back on themselves, and moreover, the extent to which the concrete actions are both ends in themselves and means to other ends is so obvious, that the abstract distinctions we have made cannot possibly delimit concrete spheres of real life"."

Dit is sekerlik nie wat Robbins in gedagte gehad het nie, in ag genome die vanselfsprekendheid dat dieselfde konkrete phenomena die empiriese veld van verskillende wetenskappe kan vorm.

Die probleem met Robbins se abstraksie is nie die abstraksie op sigself en die vorm waarin dit aangebied word nie, maar die feit dat hy nie die universaliteitsbeginsel in sy vakgebied erken nie. Later het Robbins tog egter sekere van sy idees verander." In antwoord op Sir Dennis Robertson se meer ambisieuse konsep van wat die ekonomie impliseer en waarvoor hy die term „ecfare" ontwikkel het, maak Robbins die volgende stelling: „I incline to a narrower view of what can be got out of economics alone and exhort the economist, if he hopes to be at all useful, deliberately to look outside"." Hierdeur het Robbins 'n meer gebalanseerde uitgangspunt aanvaar wat ook deurwerk na sy skrywes oor ekonomiese beleid.

'n Belangrike verskil tussen die ekonoom en ander sosiale wetenskaplikes is dat die ekonoom kyk na sy vak van binne terwyl ander wetenskaplikes dit van buite bekyk. Die ekonoom se verwysingsraamwerk is intrinsiek en hipoteties; ander wetenskaplikes se raamwerk is ekstrinsiek, transendent en holis- 
ties. Die feit dat Robbins soewereiniteit vir die ekonomie wou verkry, moes nie gelei het tot die standpunt dat dit 'n tendens is waarteen die sosioloog sowel as ander wetenskaplikes moet opstaan en vir hulle wetenskaplike lewe veg nie. ${ }^{20}$

Die abstraksie uit konkrete phenomena van daardie algemene element vir analitiese doeleindes wat jy glo jou ondersoekveld behels, sluit nie interdissiplinêre samewerking per se binne die raamwerk van dieselfde konkrete phenomena uit nie. Dit is tog immers wat interdissiplinêre samewerking impliseer.

3.1. Modale universaliteit, interdissiplinere wetenskappe en interdissiplinêre samewerking

Hierdie drie begrippe is nou verwant en word heel dikwels in hul definiëring en toepassing verwar. Veel misverstand betreffende die verband tussen die verskillende sosiale wetenskappe kan herlei word tot 'n wanbegrip van die presiese betekenis van een of almal van hierdie konsepte.

Onder modale universaliteit verstaan ons die uitdrukking van die sinskerne van ander wetenskappe binne dié van een wetenskap. Hierdie begrip vind 'n suiwerder toepassing binne die empiriese raamwerk. Byvoorbeeld, die bedryfsekonomie het as empiriese objek die bedryf en sy onmiddellike omgewing, maar hierdie empiriese veld dien as ondersoekgebied vir die sosiologie, sielkunde, sosiale sielkunde, ens. Wanneer die empiriese objek egter deur die bedryfsekonoom uit die ekonomiese aspek as abstrakte kern bestudeer word, dan word die ander betrokke wetenskappe in terme van hierdie aspek bestudeer en gebruik. Die ekonomiese is dus die kwalifiserende modaliteit, en die ander modaliteite word slegs in soverre betrek as wat hulle die ekonomiese probleem kan help verklaar of oplos. Universialiteit word hier aan soewereiniteit onderwerp.

Onder 'n interdissiplinêre wetenskap word 'n wetenskap verstaan wat sy probleem uit die probleme van verskeie ander wetenskappe haal. Goeie voorbeelde hiervan is Cybernetika en die organisasieleer. Cybernetika, met kontrole as sentrale probleem, neem 'n deel van die probleem van die ekonomiese wetenskap, sosiologie en biologie, en voeg dit in 'n algemene raamwerk en beginsels wat universele toepassing binne daardie besondere ander wetenskappe vind." Dit is 'n oorkoepelende wetenskap. 
Interdissiplinêre samewerking impliseer die byeenbrenging van verskillende vakwetenskaplikes binne die raamwerk van 'n spesifieke empiriese probleem. Hierdie tipe van samewerking vind meestal plaas in projekbeplanning, -ontwikkeling en -uitvoering.

\subsection{Objektiewe en subjektiewe motiewe in die ekonomie}

Die aard van die abstraksieproses in die ekonomie bring mee, soos reeds aangedui, dat sekere veranderlikes waaronder ook subjektiewe motiewe of die sogenaamde eksogene veranderlikes, as konstant aanvaar word. Hierdie spesifieke verhouding van objektiewe en subjektiewe motiewe vorm 'n verdere diskussiepunt tussen ekonome en ander wetenskaplikes, waaronder veral sielkundiges. In hierdie gedeelte wil ons 'n spesifieke analitiese en historiese raamwerk daarstel aan die hand waarvan verskeie standpunte beoordeel kan word.

Die ekonomiese norm of beginsel, hoe dit ook al gedefinieer word, verteenwoordig die essense van ekonomiese handeling of gedrag. Dit vorm die objektiewe motief. Subjektiewe motiewe of redes wat aanleiding gee tot ekonomiese gedrag mag 'n invloed hê op die hoe, waar en wanneer en miskien ander belangrike omstandighede rakende die ekonomiese gedrag, maar nie op wat algemeen an alle ekonomiese handelinge is nie, naamlik 'n waarde-surplus in tegniese terme. Die ekonomiese norm, of objektiewe norm, vorm dus die wat van ekonomiese gedrag; dit bepaal die inhoud van die spesifieke operasie. Wanneer die wat van ekonomiese gedrag byvoorbeeld in sosiologiese of sielkundige terme uitgedruk word, dan raak die tegniese ekonomienorm irrelevant. Dan spesifiseer die norm nie meer inhoud nie. As die wat van die handeling nie-ekonomies van aard is, dan geld slegs die rasionaliteitsbeginsel wat die manier aandui van hoe skaars middele geallokeer word. Die klem verskuif dan van inhoud na metode.

In hierdie spesifieke verhouding is die ekonomienorm die konstante faktor en die subjektiewe motiewe die veranderlike faktore. Walter Eucken het reeds hierdie onderskeid getrek toe hy van die "Wirtschaftende Menschen" gesê het dat hulle gedrag in ekonomiese planne beide konstant en veranderlik is. ${ }^{22}$ Ook John Maynard Keynes, in wie se analise sekere historiese tendense eksplisiet gekonsolideer word, maak 'n skerp onderskeid tussen objektiewe en subjektiewe motiewe. Betreffende 
hierdie subjektiewe motiewe of faktore wat hy in agt kategorieë indeel, sê hy: "There remains the second category of factors which affect the amount of consumption out of a given income - namely those subjective and social incentives which determine how much is spent, given the aggregate income in terms of wage-units and given the relevant objective factors which we have already discussed"."

Ekonome wat die konsep van die homo oeconomicus ontwikkel het, het nie die subjektiewe motiewe erken nie en het die ekonomiese gedrag alleen gesien as deur die objektiewe motief gemotiveer. Aan die ander kant het die Duitse Historiese Skool, byvoorbeeld, die bestaan van die klassieke homo oeconomicus ontken. Hulle het probeer om dit te vervang deur empiriese, historiese en sielkundige ondersoeke betreffende die subjektiewe motiewe wat tot ekonomiese aksie aanleiding gee.

Die moderne subjektiewe keuseteorie abstraheer in ' $n$ fundamenteel verskillende manier van dié van die klassieke skool. Dit abstraheer nie in die sin van die bestaan van slegs een moontlike gedragspatroon op die basis van een doelstelling nie. Nee, dit abstraheer in die sin van nie inagneming van spesifieke doelstellings van indiwiduele konkrete aksies nie. Hier is die fundamentele verskil tussen huidige ekonomiese teorie en Ludwig von Mises se aksieteorie en wat dit betref ook Talcott Parsons se sosiologiese aksieteorie. Laasgenoemdes handhaaf dat elke menslike handeling 'n doelgerigte handeling is en as sodanig hanteer moet word. Gevolglik is hierdie tipe veralgemening in die ekonomie, wat indiwiduele aksies van spesifieke doelstelling skei, skerp deur Von Mises gekritiseer.

Moderne ekonomiese teorie abstraheer uit die inhoud, en fokus dit op die algemene vorm van aksie: keuse tussen alternatiewe. Konvensionele ekonomiese teorie van ekonomiese gedrag is gebaseer op sekere aannames. Dit word aanvaar dat mense alle moontlike goedereversamelings in terme van 'n gemene maatstaf soos die bevrediging verkry, kan en wel waardeer en dat hulle dan dié kies wat die meeste satisfaksie gee.

\subsection{Ekonomie en sielkunde}

Die spesifieke abstraksiemetode soos in die ekonomie gebruik en die feit dat subjektiewe motiewe soos in die praktiese handeling tot openbaring kom nie in ag geneem word nie, het gelei tot argument onder sielkundiges dat die aannames be- 
treffende menslike motivering en gedrag waarop die ekonomiese teorie gebou is, onrealisties en dus nie aanvaarbaar is nie.

Die sielkundige skool probeer om 'n nuwe sielkundige basis vir die ekonomie te konstrueer. Die rede waarom so 'n tipe teorie nog nie algemeen aanvaar word nie, is dat die sielkundiges self nie ooreenstem oor watter sielkundige teorie die korrekte is nie. Byvoorbeeld Walter A. Weisskopf ${ }^{\text {t }}$ onderskryf 'n holistiese psychokulturele teorie, Charles R. Noyes ${ }^{3}$ 'n tipe physiologiese sielkunde, andere weer "behaviorism".

As gevolg van hierdie konfliktoestand in die sielkunde het sommige ekonome, wat hulself, as ekonome, nie bevoeg ag om tussen verskillende mededingende sielkundige teorieë te kies nie, die afhanklikheid van ekonomiese analise van sielkundige aannames geheel en al verwerp. Hulle handhaaf dat die ekonomie hom moet beperk tot die analise van die verhouding tussen empiries waarneembare data sonder om te probeer om die sielkundige prosesse onderliggend aan hierdie data te ontleed.

Moderne ekonome het egter die rol van menslike verwagtings, byvoorbeeld, ten volle in die ekonomiese analise geìnkorporeer. Ek glo nie dat ekonomiese teorie noodwendig geintegreer moet word met een of ander sielkundige teorie nie, ook is alle sielkundige proposisies nie van belang vir die ekonomie nie. Vir ekonomiese teorie, gesien in sy soewereiniteit, is dit voldoende indien die aanname gemaak kan word dat menslike gedrag in sekere praktiese areas konsekwent is. ${ }^{23}$ 'n Verklaring van totale menslike gedrag deur een wetenskap op modaliteitsvlak is onmoontlik. Die konseptuele apparaat van die ekonomiese teorie is heeltemal geskik om aan te pas by bevindings in ander wetenskappe. Dit is presies wat John Maynard Keynes in sy makro-ekonomiese indiensnameteorie gedoen het toe hy sy verbruiksfunksie soos volg geformuleer het: "The fundamental psychological law, upon which we are entitled to depend with great confidence both a priori from our knowledge of human nature and from the detailed facts of experience, is that men are disposed, as a rule and on the average, to increase their consumption as their income increases, but not by as much as the increase in their income"..

Op grond van hierdie sielkundige aanname kon Keynes deur middel van sy ekonomiese model sekere vooruitskattings maak. Dit wil nie sê dat in dieselfde ekonomiese apparaat nie ' $n$ ander aanname in die plek van hierdie een gestel kan word 
nie. Dit is wat Dorothy Brady en Rose Friedman gedoen het met die ontwikkeling van hulle relatiewe inkome-hipotese in plaas van die bogenoemde absolute inkome-hipotese van Keynes. Dit is ook wat Milton Friedman en Franco Modigliani beoog het met hulle permanente inkome-hipotese.

Dit alles toon dat die tradisionele ekonomiese analitiese apparaat gebruik kan word met alternatiewe en onderlinge eksklusiewe sielkundige aannames. Dit is so omdat ekonomiese teorie as sodanig alleen met die onderlinge verhoudings tussen veranderlikes werk. Die proposisies is geldig vir 'n serie van verskillende situasies waarby keuse tussen alternatiewe betrokke is en kan dus in algemene terme gestel word. Die betekenis wat aan die simbole en konsepte geheg word, word deur die observasie en klassifisering van werklike keusesituasies bepaal. Werklike keuses deur indiwidue gemaak varieer vanselfsprekend met sosiale struktuur, fisiese omgewing, instellings, geloof en ander subjektiewe faktore, in kort, met die sosiale en kulturele raamwerk waarbinne keuses gemaak word. So varieer die waarde van sielkundige hipoteses soos in die ekonomie gebruik ook binne die raamwerk van bogenoemde omgewingsfaktore. Die waarde van die element $b$ in die Keynesiaanse verbruikfunksie van $\mathrm{V}=\mathrm{a}+\mathrm{bY}$ sal varieer afhangende van hierdie omstandighede.

\section{Gevolgtrekking}

Elke sosiale wetenskap het 'n soewereiniteitsgebied soos deur 'n sinskern onderskei. Abstrakte teoretiese analise binne 'n modale raamwerk is uiteraard ,onrealisties" wanneer die volle konkrete situasie betrek word. Die totale werklikheid kan nie uit die oogpunt van een modaliteit verklaar word nie. Om ' $n$ empiriese probleem in al sy aspekte te verklaar verg 'n geïntegreerde teoretiese en konseptuele raamwerk. Dit kan op twee wyses gedoen word. Eerstens kan so 'n geintegreerde teorie opgebou word uit algemeenhede en beginsels wat alreeds in die verskeie wetenskappe ontwikkel is. Hierdie benadering toon nog nie veel sukses nie as daar na die vroeë institusionalisme in die ekonomie gekyk word. Dit lyk ook nie of die neoinstitusionalisme in die sosiologie, waarin getrag word om die ekonomie en die sosiologie te integreer, enige noemenswaardige aanhang geniet nie. Ook Ludwig von Mises se teorie van die menslike handeling het nie veel praktiese toepassing gevind nie. 
Die tweede manier om 'n geïntegreerde teorie daar te stel is deur middel van 'n algemene sisteembenadering tot die kompleks sosiale phenomena. Dit impliseer dat die ekonomiese en ander sosiale wetenskappe slegs subsisteme van die totale sisteem vorm. Hierdie benadering is nog in sy kinderskoene, maar dit is te betwyfel of ' $n$ algemene teorie van die totale sosiale sisteem hieruit sal voortvloei.

Dit lyk egter of 'n analise van die sosiale lewe onmoontlik is sonder die konstruksie van parsiële endogene sisteme binne die raamwerk van indiwiduele modaliteite. Die ekonomie is dus ten volle geregtig om in terme van sy soewereine gebied die behoeftes, die middele en die beste tegnologie as data te aanvaar in die opbou van teoretiese modelle ter verklaring van een aspek van die hele kompleks van sosiale verhoudings. Wat die praktiese toepassing en gebruik van die resultate van so 'n model betref, moet daar 'n duidelike insig wees in die voorwaardes en beperkings van so 'n model. Daardie aspekte uit die ander sosiale wetenskappe wat nie as elemente of endogene faktore in die ekonomiese teorie geïnkorporeer kan word nie, geld as eksogene en beperkende omstandighede. Hierdie siening is gebaseer op praktiese realiteit, sosiale kompleksiteit en blote sistematiek. Die twisgeskryf in die literatuur oor die inagneming van alle veranderlikes deur die ekonomie laat die vraag ontstaan: hoekom moet daar dan ekonomie of sielkunde of sosiologie wees, hoekom nie net een sentrale en geïntegreerde sosiale wetenskap nie, en uiteindelik hoekom dan nie slegs wysbegeerte nie? Die fundamentele verskeidenheid in die kosmos word baie keer heeltemal buite rekening gelaat.

Die spil waarom dit eintlik draai is dat die fraksionele aard van die ekonomiese teorie erken moet word en dat dit in die totale situasie aan die hoër modale orde onderwerp moet word.

Baie misverstand in die literatuur is gegrond op wanopvattings betreffende die definiëring, toepassing en implikasies van die begrippe soewereiniteit in eie kring, universaliteit in eie kring, die onderwerping van universaliteit aan soewereiniteit, interdissiplinêre wetenskappe en interdissiplinêre samewerking.

Wat die realiteit van die aannames in die ekonomie betref, gaan dit tog nie om die realiteit as sodanig nie maar om die krag van voorspelbaarheid van die teorie.

Laastens: Vra die huidige dooiepunt oor die daarstelling van endogene normatiwiteit in die ekonomie nie om nuwe 
insigte en ontleding van hierdie probleem nie? Kan daar nie sprake wees van 'n eksogene normatiwiteit wat gebaseer is op 'n spesifieke lewens- en wêreldbeskouing en sodoende uit die totaalsituasie op die ekonomie as onderdeel afgedruk word nie? Is die ekonomie 'n normatiewe wetenskap omdat daar norme in die interne struktuur ingewerk is (wat nie die geval is vandag nie) of is dit ' $n$ normatiewe wetenskap omdat die ekonoom as mens met 'n Christelike lewens- en wêreldbeskouing die feitlike ekonomie normatief interpreteer en toepas? Daar sal sekerlik meer tyd en energie in hierdie rigting aangewend moet word

Dept. Bedryfsekonomie, N. J. Swart. P.U. vir C.H.O.

1 Vergelyk Milton Friedman: Essays in Positive Economics. Chicago, University Press, 1960, p. 16 e.v.; Fritz Machlup: The problem of verification in economics, Southern Economic Journal, Julie 1955, pp. 1-21; F. Machlup: Theories of the firm: marginalist, behavioral, managerial, American Economic Review, Maart 1967, pp. 1-33; Jack Melitz: Friedman and Machlup on the Significance of testing economic assumptions, Journal of Political Economy, Feb. '1965, pp. $37-60$; P. A. Sameulson: Discussion on methodology, American Economic Review, Proceedings, Mei 1963, pp. 231-36; Fritz Machlup: Professor Sameulson on theory and realism, American Economic Review, Proceedings, Mei 1963, pp. 231-36; Fritz Machlup: Professor Sameulson on theory and realism, American Economic Review, Sept. 1964, pp. 733-5; Lionel Robbins: Live and dead issues in the methodology of economics, Economica, Aug. 1938, p. 348.

2 Vergelyk John R. Commons: Institutional Economics, New York, Macmillan, 1934. Sien ook W. H. Hamilton: The Institutional Approach to Economic Theory. American Economic Review, 1919, pp. $300-318$.

3 Commons: op. cit., pp. 58-59.

4 Talcott Parsons en Neil J. Smelser: Economy and Society, New York, Free Press, 1965.

5 L. M. Fraser: Economic Thought and Language, Londen, Adam and Charles Black, 1947. Sien veral ook Israel M. Kirzner: The Economic Point of View, Princeton, D. von Nostrand, 1960.

6 Lionel Robbins: The Nature and Significance of Economic Science, London, Macmillan, 1948

7 Robbins: op. cit., p. 12.

8 Robbins: op. cit., p. 76.

9 Robbins: op. cit. pp. 77-8.

10 Robbins: op. cit., p. '16.

11 L. M. Fraser: op. cit., p. 30. 
12 Robbins: op. cit., p. 34. Fraser: op. cit., p. 31. Sien ook Robert Dorfman, P. A.: Sameulson en Robert Solow: Linear Programming and Economic Analysis, 1958, p. 202. Souter, Parsons en Rivett het hierdie onderskeid tussen die ekonomiese en die tegniese in twyfel getrek.

13 Baie tyd en energie is in die literatuur aan hierdie aspek gewy. Vergelyk die artikels in De Economist van 1926 tot 1965 . Sien ook T. W. Hutchison. Positive Economics and Policy Objectives, 1964, asook die klassieke werk van I. M. D. Little, A Critique of Welfare Economics, Clarendon Press, 1950.

14 R. W. Souter: The Nature and Significance of Economic Science in Recent Discussions, Quarterly Joumal of Economics, Mei 1933, pp. 377-413. Dieselfde outeur se Prolegomena to Organics of an Expanding Economic Universe, 1933 kan as 'n uitbreiding van hierdie artikel gesien word.

15 Talcott Parsons: Some Reflections on 'The Nature and Significance of Economics', Quarterly Journal of Economics, Mei 1934, pp. 511-45.

'16 Parsons: op. cit., pp. 533-4.

17 Parsons: op. cit., pp. 529-30.

18 Lionel Robbins: The Economist in the Twentieth Century, Economica, Mei 1949 , pp. 93-105

19 Sien Robbins se diskussie van Sir Dennis Robertson se Utility and All That and Other Essays in sy artikel Robertson on Utility and Scope, Economica, Mei 1953, p. 111.

20 Parsons: op. cit., p. 535.

21 Daar kan nie hier op die struktuur van interdissiplinére wetenskappe ingegaan word nie. Vir 'n fundamentele en detail-analise in dié verband, sien Erich Kosiol, Zum Standort der Systemfor. schung im Rahmen der Wissenschaften, Zeitschrift für betriebs. wirtschaftliche Forschung, Julie 1965, pp. 337-376.

22 Walter Eucken: Die Grundlagen der Nationalökonomie, 1943, p. 266.

23 J. M. Keynes: The General Theory of Employment, Interest and Money, New York, Harcourt, Brace and World, 1935, p. 107.

24 W. A. Weisskopf: The Psychology of Economics, 1955.

25 C. R. Noyes: Economic Man in Relation to his Natural Environment, 1948.

26 Sien F. H. Knight: Professor Parsons on Economic Motivation, The Canadian Journal of Economics and Political Science, Aug. 1940, pp. 460-65. Sien ook in dieselfde volume van hierdie tydskrif, Talcott Parsons: The Motivation of Economic Activities, pp. 187-202. In hierdie artikel probeer Parsons deur die teorie van institusies as uitgangspunt te neem, om die ekonomie in die breër sisteem van die teorie van aksie te plaas. Sien verder Talcott Parsons: Reply to Professor Knight: Canadian Journal of Economics, Aug. 1940, pp. $466-472$.

27 Keynes: op. cit., p. 96.

28 Sien James G. Miller: Living Systems: Basic Concepts, Behavioral Science, Julie 1965, pp. 193-237. Ook dieselfde outeur se Living Systems: Structure and Process, Behavioral Science, Okt. 1965, pp. 337-380 en sy Living Systems: Cross-Level Hypothesis, Behavioral Science, Nov. 1965, pp. 380-411. 